\title{
Gender differentials in poverty among migrants in rural border communities of Oyo state, Nigeria
}

\author{
Kehinde Olayinka Popoola ${ }^{1, *}$, Gbenga John Oladehinde ${ }^{1}$, Eniola Animasaun ${ }^{2}$
}

${ }^{1}$ Obafemi Awolowo University, Faculty of Environmental Design and Management, Department of Urban and Regional Planning, Nigeria

2 University of Ibadan, Institute of African Studies, Nigeria

* Corresponding author: yinkaolayiwola@yahoo.co.uk

\begin{abstract}
The study examined relative poverty among migrant men and women in rural border communities of the Oyo State. Three rural border settlements were randomly selected in Atisbo and Saki-west Local Government Areas (LGAs) of Oyo State. Two hundred and four (204) questionnaires were administered to the father and mother in 102 migrant households and 198 questionnaires were retrieved for analysis. Using Principal Component Analysis (PCA), the study revealed that women have a higher poverty level than men. Also, the Principal Component Analysis revealed that the high loadings of factors on component one (Dwelling Conditions), for both men and women, imply inadequate living conditions. This indicates the need for improved dwelling conditions for the migrants and also the need to focus on gender-based poverty interventions especially among females, as they are more affected by poverty.
\end{abstract}

\section{KEYWORDS}

poverty; gender; migrants; border communities; rural communities

Received: 3 December 2020

Accepted: 17 June 2021

Published online: 2 October 2021 


\section{Introduction}

Poverty has been described from different dimensions, for example, World Bank (1990) viewed poverty as the inability to attain a minimum standard of living. Sen (1999) described poverty as the failure to achieve basic capabilities such as being adequately nourished, living a healthy life, possessing skills for economic and social life participation, and allowance to take part in community activities. It is also described as lack of access to health, school, employment, and clean water (DFID 2005 and Chambers 2006). Poverty is also seen as a mindset, a perception of what rural poor have of themselves, the local community, the society, and the country as a whole (IFAD 2007).

Gender is an integral and very important part of any poverty study. IFAD (2007) described gender and rural poverty as a process within which human beings develop and exhibit social and behavioral patterns that shape their actions and relationships within and outside their homes and communities. In studying poverty, it is necessary to integrate gender dimension into it. In other words, it is very important to study poverty in line with gender and gender relations. Gender is defined as different social roles men and women play and the power relations between them (Lyimo-Macha and Mdoe 2002) while gender relations are the opportunities, constraints, and impacts of change as they affect men and women. It is also a determinant of how communities, households, and institutions are organized, how decisions are made, and how resources are used. This means the application of traditional gender relations to poverty implies differentiation in poverty between men and women.

Poverty is very severe in rural areas (IFAD 2007). One of the reasons for this is linked to non-existent or limited social services and infrastructure in the areas. Rural border areas are like many other rural communities in Nigeria. Popoola and Speak (2018) explained that most rural border communities of Nigeria are neglected with limited access to amenities and facilities. They are therefore underdeveloped as other rural communities in Nigeria. However, despite the poor condition of the border communities, many migrants (especially those from the neighbouring countries) are still resident in the border communities. In rural communities, most migrants are faced with lots of challenges such as difficulties in getting good jobs, poorer living conditions, discrimination, and limited access to better opportunities (FAO 2019). International Organization for Migration (IOM) 2019 asserted that migrants often lack effective protection from harm and are also characterized with fewer rights such as the right to work, housing, and health among others. United Nations (2013) emphasized the protection of migrants' rights in destination countries. The policy states that "all migrants and their families irrespective of their migratory status have series of rights in their destination countries." Adequate standard of living is one of the migrants' rights and must be put into consideration during border studies.

Although previous studies have offered substantial insight on poverty issues (Gweshengwe and Hassan 2020; Chen and Pan 2019; Koehler 2017; Ogbonna et al. 2012; Chambers 2007), yet there has been little concerted effort to incorporate gender into poverty studies. Also, understanding gender is core in the poverty context because poverty studies have traditionally emphasized the power relation between men and women as well as the differences in social roles that men and women play. In addition, studies from Asia countries have argued that the experiences of migrant men and women vary and most of the variations are due to the role, behaviour, and relationships that the society assigns to and expects from a man and a woman (Strachan at al. 2015; Yichao and Di 2017; Hao et al. 2021). Nonetheless, this might be different in Sub-Saharan African countries due to cultural and political differences. Besides, there is a dearth of information on poverty studies using gender framework in rural border communities of Nigeria.

From the foregoing, it is very important to examine poverty variation of migrants in rural border communities. However, this might be more explained by gender. This study aims to investigate poverty among migrants in rural border communities of Oyo State, Nigeria. This was with the purpose of highlighting the implications of such variations between the genders in the study area. In achieving the aim, the research provides answers to the following questions: 1) What is the poverty level of men and women in the study area? 2) Is there any significant difference in poverty level among men and women? 3) Is there any variation in the poverty level of men and women across the settlements in the study area.

\section{Literature Review}

Many studies have been done on Border communities (Jawando et al. 2012; Awumbila 2015; Popoola et al. 2017; Nkoroi 2015; Apata et al. 2010, Anyebe 2017). However, studies on gender and poverty in rural border communities of developing countries like Nigeria are scanty in literature. For instance, Jawando et al. (2012) examined survival strategies of women in informal cross-border trading along Lagos-seme Border Axis. The study revealed that women faced a lot of challenges in trying to transport their goods from customs officials and other security agents. Despite these difficulties, they still engage in this informal trade along this border.

Also, Popoola et al. (2017) investigated gender analysis of cross-border migration in rural border communities of Ipokia Local government area, Ogun State, Nigeria. The study shows that good access to land, commerce, and better income reasons were the major considerations for choosing destination area by 
male migrants while good access to land, marriage, to join family members and better income were the considerations for choosing destination area by female migrants in Nigeria. The study concluded that despite the increase in cross-border migration in the study area, patterns and reasons for cross-border migration vary between men and women.

Also, other studies (Makinwa-Adebusoye 1994; Fapohunda 2012; Ogbonna et al. 2012; Adeyonu and Oni 2014) that addressed the issue of gender and poverty did not focus on rural border region especially rural border region of Nigeria. Makinwa-Adebusoye (1994) assessed women migrants in Nigeria. The study discovered that women, as well as men, do migrate for the same reasons - mainly to seek remunerative employment in order to meet personal as well as socially ascribed financial obligations to children and relatives. Other reasons that were added by the study include the need to further education or for learning a trade as an apprentice. The study concluded that the importance of migration to family survival at the place of origin facilitates the migratory process and adjustment to the new destination. Usman (2015) examined women and poverty in Nigeria. The study argued that, although women contribute greatly to societal growth and development, they have continued to suffer unjustly in the precarious condition of poverty due to their underprivileged class position in society. The study concluded that unless some drastic steps were urgently taken to eradicate poverty in the country, its perpetuity may have future catastrophic consequences. Anyebe (2017) examined gender differential and poverty amongst women in Nigeria. The study revealed that only a very tiny proportion of women do get into commanding heights of national life for which higher education is a prerequisite. The study recommended that education for women and girls at all levels should aim at reversing the trend of gender discrimination by ensuring full empowerment of women in the true sense of raising their status. Although the above literature provided some sound footings to this study on gender and migration in border communities, issues of gender and poverty have not been properly documented.

Also, studies on poverty Alaye-Ogan (2008), Ayoade and Adeola (2012), Fadare and Gasu (2011) and Ogbonna et al. (2012) have little or no gender perspectives to them. For instance, Alaye-Ogan (2008) assessed rural poverty among women in Nigeria, using Abuja Satellite Communities as a case study. The findings of the research revealed that rural women in Nigeria were more prone to poverty. The study also showed that poverty is multidimensional in nature and recommended that any effective strategy to tackle it must be multi-dimensional to be effective. This study however only focussed on women, Thus making it inadequate for better comparison between men and women. Similarly, the study of poverty in the hinterlands of Ede, Nigeria by Fadare and Gasu (2011) was based on the assessment of household poverty status and the important indicators that explained the variation in the poverty status. The study revealed that the combinations of the various factors (Agric-business, Environmental impact, Health factors, and Environmental Awareness) constituted the indicators that gave the most appropriate explanations underlying the variation of relative poverty among the households in the region. This study did not assess the poverty status and indicators by gender. Ayoade and Adeola (2012) examined the effects of poverty on rural households in Orire Local Government Area of Oyo State, Nigeria. The findings of the study revealed that the major effects of poverty on rural households were the low standard of living and low-income level. Ogbonna et al. (2012) examined the factors influencing households' exit from poverty as a guide for policy intervention in the increase in yam production among yam-producing household heads. The paper discovered that the determinants of poverty were level of education, membership of farmer's group, yam production experience, and participation in the agricultural workshop. These factors significantly decreased poverty but the household dependency ratio was discovered to increase poverty. However, their evaluations were not done along gender lines. Studies on poverty must therefore see households and communities as gendered units in which women and men have different sets of interests.

\section{The study area}

The study areas are situated in Oyo State South-Western Nigeria. Oyo State was created in February 1976 by the Federal Military Government of Nigeria. The State covers an area of approximately 35,743 square kilometers. It is located between latitudes $7^{\circ} 22^{\prime}$ and $7^{\circ} 40^{\prime}$ North of the Equator and longitudes $3^{\circ} 53^{\prime}$ and $4^{\circ} 10^{\prime}$ East of the Greenwich. It is bounded in the south by Ogun State, in the north by Kwara State, in the west it is partly bounded by Ogun State and partly by the Republic of Benin, while in the East by Osun State (Figure 1). Oyo State has thirty-three (33) local government areas out of which Saki-west and Atisbo local government areas selected for this study are located. Atisbo and Saki - west LGAs were selected for this study because they share boundary with other countries (Figure 2).

Rural border communities selected for this study are located in Atisbo and Saki West Local government areas. The rural border communities are typical rural settings with the majority of the settlements having less than 20,000 populations, and the economic activity predominantly agrarian. The major occupation of the people in the communities is arable farming. Other livelihood activities in the areas are trading, smuggling activities. One of the peculiarities of the border area is the culturally heterogeneous nature 
of the area. Therefore, for the purpose of this study, migrants selected in the rural border areas of Oyo State were used to investigate and show the gender variations in poverty in selected rural border communities of Oyo state. The location of Oyo State in the context of Nigeria is shown in Figure 1.

\section{Methodology}

Extensive reconnaissance survey of two borders Local Government Area (LGA) that made-up the only border LGA in Oyo State was carried out. This provided a direct opportunity to identify major settlements with higher proportion of migrants. The primary data used in this research were sourced through field survey that was conducted with questionnaire administration, interview, and field observation. One set of questionnaires was used to obtain relevant data from a father and mother in each household. The questionnaire contains questions that were used for collecting only the information required for the computation of the global multidimensional poverty index (Alkire et al. 2020).

The research made use of primary data. The primary data were obtained through questionnaire administered in the selected rural border communities of
Oyo State, South-Western Nigeria (SWN) using a multistage sampling technique. In the first stage, two local government areas were purposively selected in the state based on their closeness to the border (Saki west and Atisbo in Oyo State) as shown in Figure 2. The second stage involved the random selection of three rural border settlements in each of the selected local government areas. In the third stage, migrant households were selected through snowball sampling approach (Naderifar et al. 2017). This approach was used to ensure that only migrants were selected for this research. The procedure involved the selection of the first migrant. The selected migrant later referred the researcher to another migrant who is not from the community. This procedure continues until the researcher had administered questionnaire on all the contacts. At the end of the questionnaire administration, a total of one hundred and two (102) migrant households were surveyed and two hundred and three (203) questionnaires were administered to father and mother in each selected household. Where the two (father and mother) were not available, either of the two was also sufficient for the study. One hundred and ninety-eight (198) questionnaires were retrieved for the analysis. Data collected through questionnaires were focused on the living condition of a father and mother in each household.

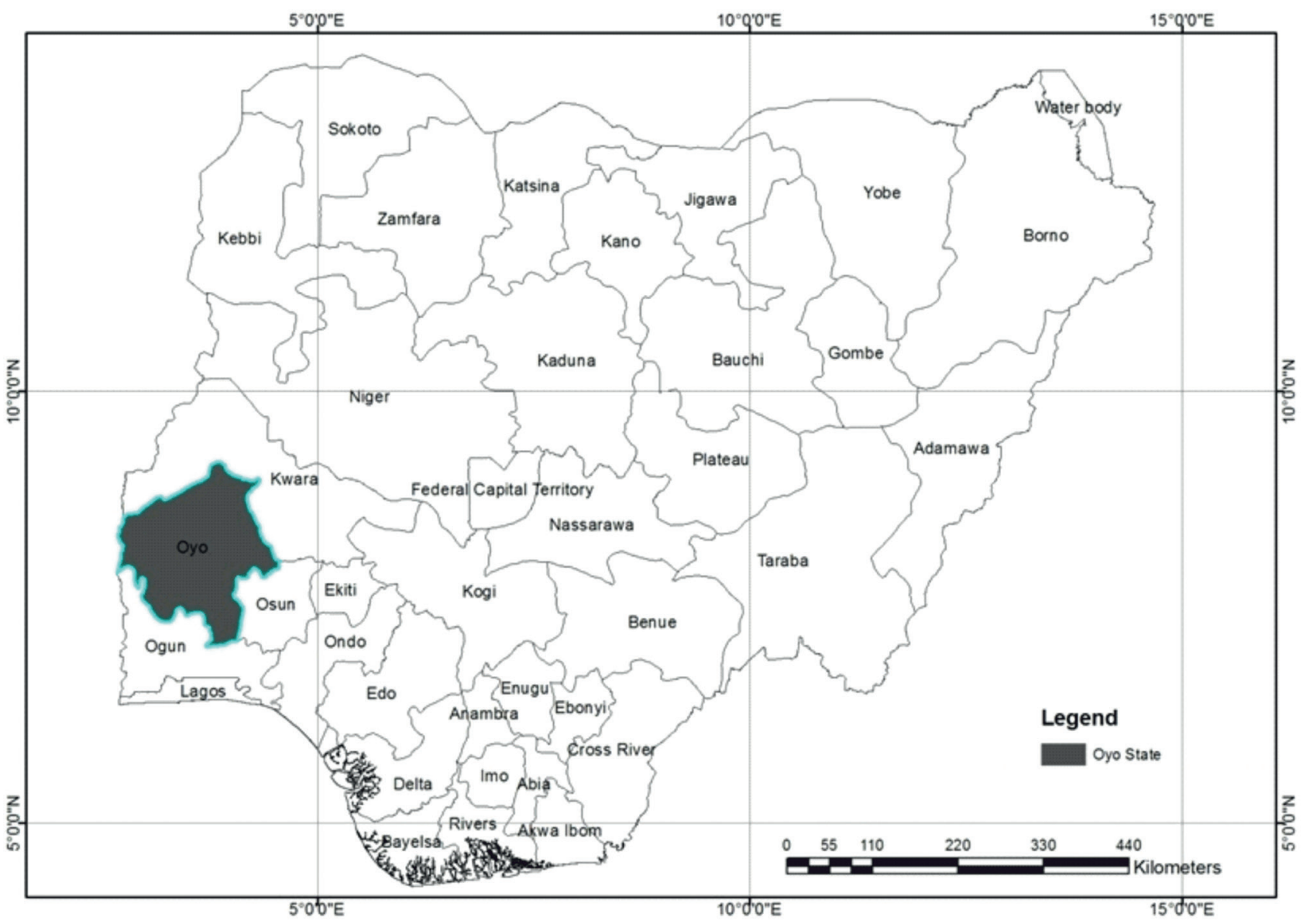

Fig. 1 Location of Oyo in the context of Nigeria. 


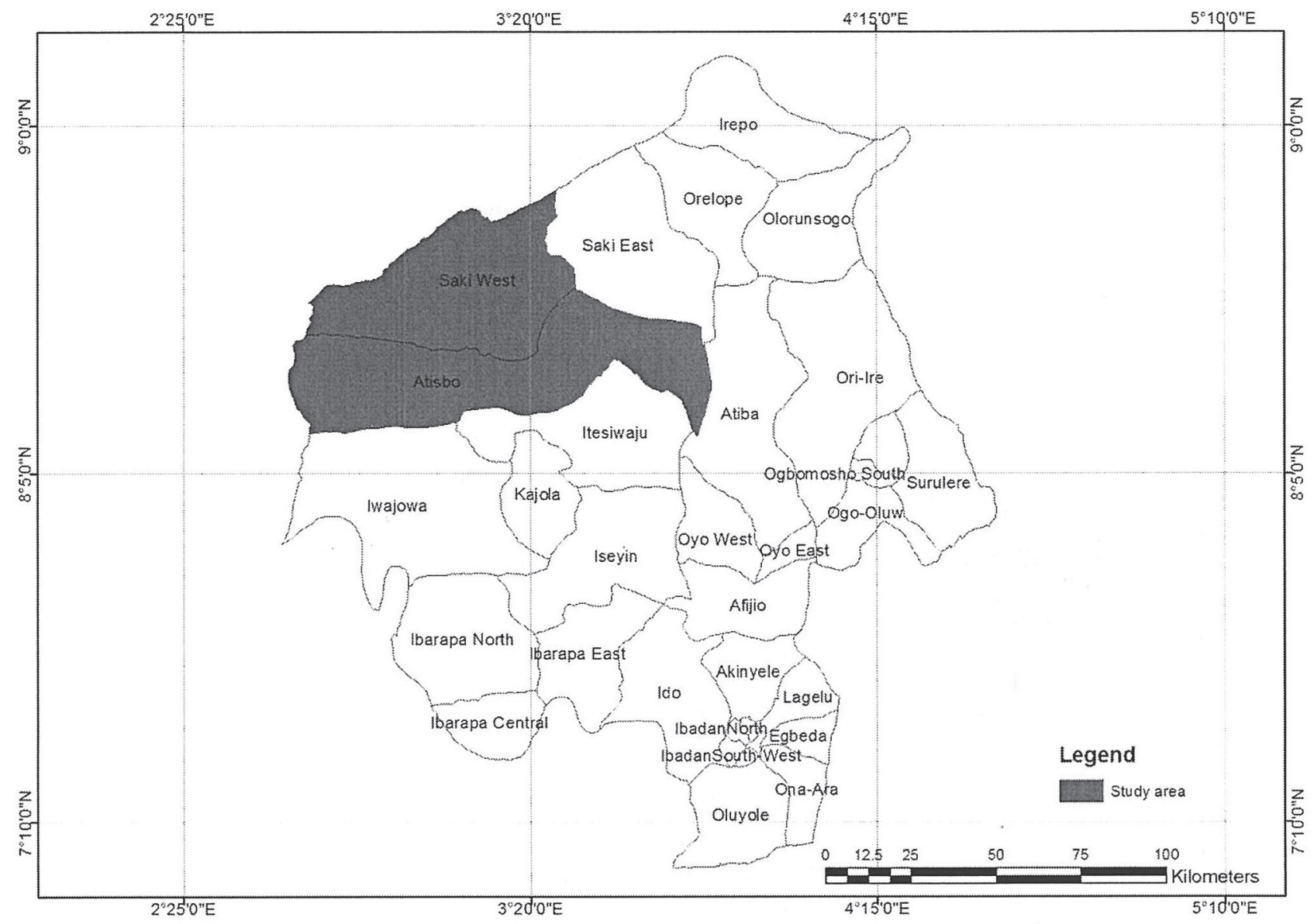

Fig. 2 Location of Atisbo and Saki West Local Government Areas in the context of Oyo State.

The instrument for the interview was a self-administered questionnaire. Open-ended as well as semi-structured questions were formed to extract information from the respondents. The questions were properly revised by a specialist to know the applicability of the question in determining the indicators that were established in the literature before it was administered to the respondents. The questionnaire was administered face to face with the respondent.

The final instrument has three sections: (a) standard of living (b) health and (c) education. The first set of questions captured the standard of living of the respondents. Standard of living was assessed by asking respondents about their annual income; the number of relative that depends on them. Respondents were then asked about their source of farm labour. Respondents were also asked about different materials that are being used for house construction; materials for Roofing; materials for floor and sources of indoor illumination. The second set of questions asked respondents about the method of treating their health and the number of meals per day. The third set of questions were on education. Respondents were asked about the number of years spent in school. All the questions were semi-structured and were obtained as continuous variables.

\section{Material}

This paper presents the findings of an empirical research study designed to investigate variations in the poverty level of men and women. In doing so, the researchers sought to document different indicators in measuring poverty levels. An assessment of the dimension of poverty was based on the works of International Fund for Agricultural Development (IFAD) (2014), Alkire and Foster (2011), Alkire and Sumner (2013), Oxford Poverty and Human Development Initiative (OPHI) (2018), United Nations Development Programme and Oxford Poverty (UNDP) and OPHI (2020). IFAD (2014) identifies some proxies for measuring poverty levels from academic literature and several other organizations. These include food and nutrition security; domestic water supply; health and health care; sanitation and hygiene; housing, clothing, and energy; education; farm assets; non-farm assets; exposure and resilience to shocks; gender and social equality. OPHI (2018) regrouped these dimensions into three dimensions of poverty, namely: Health (nutrition and child mortality), Education (years of schooling and school attendance), Living standard (cooking fuel, sanitation, drinking water, electricity, housing, and assets). The regrouped dimension of poverty was adopted by UNDP and OPHI 
(2020) to develop global MPI in charting pathways out of multidimensional poverty to achieve the SDGs. The consolidated indicator as adopted by UNDP and OPHI (2020) is therefore considered for this study. Below are the number of variables for establishing poverty levels (Table 1 ).
State, Nigeria. There are many indicators for measuring the poverty level of men and women. This study considered 10 indicators and are categorized under health (methods of treatment and number of meals per day), education (years of schooling), and living standard (annual income, number of depend-

Tab. 1 Indicators of measuring multidimensional poverty.

\begin{tabular}{|c|l|l|l|}
\hline S/N & Dimensions of Poverty & Indicator & Details \\
\hline 1 & Health & Treatment of health & Ways of treating their health \\
\hline 2 & Education & Number of meals per day & Number of meals per day \\
\hline 3 & Living standard & Year of schooling & Number of years spent completing schooling \\
\hline & & Number of relative dependents & The total amount of money received in a year \\
\hline & & Source of farm labour & Number of the relative that depends on them \\
\hline & & Materials used for house construction & Sources of farm labour \\
\hline & & Materials for roofing & Types of material that is used for roofing \\
\hline & & Materials for floor & Types of material that is used for floor \\
\hline & & Source of illumination & Sources of indoor illumination \\
\hline
\end{tabular}

Source: Adapted from UNDP and OPHI (2020)

\section{Data Analysis}

Data obtained were analyzed using a number of analytic methods from the SPSS package like Inferential statistics (such as Principal Component Analysis, t-test, and ANOVA) and Descriptive statistics (such as frequencies, percentages, and bar graph). Descriptive statistics were used to analyze the poverty grouping by gender and poverty levels of men and women across the border settlements. Principal component analysis (PCA) was used to establish relative poverty index and poverty classes of (low, medium, and high) that were differentiated by gender as used by Henry et al. (2003). ANOVA and t-test were used to test differences in the average poverty score between males and females as well as the differences in poverty index of males and females across the settlements through the formulation of the hypothesis (Oladehinde et al. 2017).

In this study, two hypotheses were formulated. The first hypothesis states that "There is no significant difference in the poverty level among men and women" while the second hypothesis states that "There no variation in the poverty level of men and women across the settlements in the study area". The first hypothesis was determined through the use of t-test while ANOVA was used to determine the second hypothesis.

\section{Results and discussions}

This study examined poverty among migrant men and women in rural border communities of Oyo ent relatives, materials for construction, roofing materials, floor materials, sources of illumination, and sources of farm labour). Principal component analysis (PCA) was used to show the underlying component that is calculated. It was further used to represent a linear combination of the indicator variables used in the model. The results of the PCA model include four tables: the component rotated matrix, the common variance table, the communalities table, and the Kaiser-Meyer-Olkin (KMO-Bartlett) test.

The Kaiser-Meyer-Olkin measure of sampling adequacy is an index for comparing the magnitudes of observed correlation coefficients with the magnitudes of partially correlated coefficients. The smaller the value of the index, the less appropriate the model while scores of 0.50 are considered poor, above 0.60 are acceptable, above 0.70 are good, above 0.80 are commendable and above 0.90 are exceptional (Henry et al. 2003; Ahadzie et al. 2008).

Tables 2 and 3 show the results of the Kaiser-Meyer-Olkin-Bartlett's test of sampling adequacy with value of 0.610 for men and 0.679 for women which are within the acceptable range for the well-specified model.

Tab. 2 KMO and Bartlett's test table (Men).

Kaiser-Meyer-Olkin Measure of Sampling Adequacy. .610

\begin{tabular}{|c|r|} 
Approx. Chi-Square & 236.703 \\
\hline Df & 45 \\
\hline Sig. & .000 \\
\hline
\end{tabular}

Source: Computer output 
Tab. 3 KMO and Bartlett's test table (Women).

\begin{tabular}{|l|c|r|}
\hline \multicolumn{2}{|c|}{ Kaiser-Meyer-Olkin Measure of Sampling Adequacy. } & .679 \\
\hline \multirow{3}{*}{ Bartlett's Test of Sphericity } & Approx. Chi-Square & 233.443 \\
\cline { 2 - 3 } & Df & 45 \\
\cline { 2 - 3 } & Sig. & .000 \\
\hline
\end{tabular}

Source: Computer output

The size of communalities represents the strength of the linear association among variables and components and it is a very important test of the appropriateness of the poverty model. Henry et al. (2003) explained that Communalities indicate how the indicators combine to identify different components. The value of communalities ranges between 0 and 1 and higher observed values represent a greater share of common variance which is explained by the extracted components. Table 4 showed that communalities range in value from 0.314 and 0.742 for men and 0.322 and 0.835 for women are considered to fall within an acceptable range ( 0 and 1 ). 0.314 and 0.322 being the least values and 0.742 and 0.835 being the highest value of communalities in Table 4. This represents a greater share of common variance. Variables with high values were well represented in the common factor space while variables with low values were not well represented. All the indicators proved highly explanatory of the poverty components shown in Table 4.
Tab. 4 Communalities.

\begin{tabular}{|l|c|c|c|c|}
\hline \multirow{2}{*}{} & \multicolumn{2}{|c|}{ MALE } & \multicolumn{2}{c|}{ FEMALE } \\
\cline { 2 - 5 } & Initial & Extraction & Initial & Extraction \\
\hline Annual income & 1.000 & .526 & 1.000 & .697 \\
\hline $\begin{array}{l}\text { Number of dependent } \\
\text { relatives }\end{array}$ & 1.000 & .656 & 1.000 & .470 \\
\hline Materials for construction & 1.000 & .742 & 1.000 & .807 \\
\hline Roofing materials & 1.000 & .703 & 1.000 & .835 \\
\hline Floor materials & 1.000 & .628 & 1.000 & .736 \\
\hline Source of illuminations & 1.000 & .605 & 1.000 & .460 \\
\hline Method of treatment & 1.000 & .520 & 1.000 & .483 \\
\hline Years of schooling & 1.000 & .314 & 1.000 & .442 \\
\hline Number of meals per days & 1.000 & .634 & 1.000 & .322 \\
\hline Source of farm labour & 1.000 & .538 & 1.000 & .346 \\
\hline
\end{tabular}

Extraction method: Principal component analysis

Source: Computer output

Table 5 and 6 showed four-level components of PCA with Eigenvalues greater than 1.0 extracted using the factor loading of 0.50 as the benchmark of explained "Common Variance" to be considered representative of a common underlying dimension. The size of an Eigenvalue represents the amount of variance in the PCA explained by the component, hence the larger the Eigenvalue, the more that component is explained by the model's indicators (Henry et al. 2003). In other words, the first four components of PCA with eigenvalues

Tab. 5 Total variance explained for men.

\begin{tabular}{|c|c|c|c|c|c|c|}
\hline \multirow{2}{*}{ Component } & \multicolumn{3}{|c|}{ Initial eigen values } & \multicolumn{3}{|c|}{ Extraction sums of squared loadings } \\
\hline & Total & $\%$ of variance & Cumulative \% & Total & $\%$ of variance & Cumulative \% \\
\hline 1 & 2.811 & 28.114 & 28.114 & 2.811 & 28.114 & 28.114 \\
\hline 2 & 1.815 & 18.146 & 46.260 & 1.815 & 18.146 & 46.260 \\
\hline 3 & 1.238 & 12.383 & 58.642 & 1.238 & 12.383 & 58.642 \\
\hline 4 & 1.019 & 10.186 & 68.828 & 1.019 & 10.186 & 68.828 \\
\hline 5 & .733 & 7.326 & 76.154 & & & \\
\hline 6 & .654 & 6.536 & 82.689 & & & \\
\hline 7 & .585 & 5.853 & 88.542 & & & \\
\hline 8 & .487 & 4.865 & 93.407 & & & \\
\hline 9 &. .440 & 4.402 & 97.809 & & & \\
\hline 10 & .219 & 2.191 & 100.000 & & & \\
\hline
\end{tabular}

Extraction method: Principal component analysis

Source: Computer output 
Tab. 6 Total variance explained for women.

\begin{tabular}{|c|c|c|c|c|c|c|}
\hline \multirow{2}{*}{ Component } & \multicolumn{3}{|c|}{ Initial eigen values } & \multicolumn{3}{|c|}{ Extraction sums of squared loadings } \\
\hline & Total & $\%$ of variance & Cumulative \% & Total & $\%$ of variance & Cumulative \% \\
\hline 1 & 2.944 & 29.441 & 29.441 & 2.944 & 29.441 & 29.441 \\
\hline 2 & 1.508 & 15.084 & 44.524 & 1.508 & 15.084 & 44.524 \\
\hline 3 & 1.146 & 11.457 & 55.981 & 1.146 & 11.457 & 55.981 \\
\hline 4 & 1.069 & 10.686 & 66.667 & 1.069 & 10.686 & 66.667 \\
\hline 5 & .922 & 9.221 & 75.888 & & & \\
\hline 6 & .727 & 7.267 & 83.155 & & & \\
\hline 7 & .645 & 6.453 & 89.608 & & & \\
\hline 8 & .526 & 5.258 & 94.866 & & & \\
\hline 9 & .304 & 3.039 & 97.904 & & & \\
\hline 10 & .210 & 2.096 & 100.000 & & & \\
\hline
\end{tabular}

Extraction method: Principal component analysis

Source: Computer output

greater than 1 as seen in Tables 5 and 6, account for high variance while those components with an eigenvalue of less than 1 account for less variance. The total variance explained by each component extracted in Table 5 (men) and Table 6 (women) are as follows: the first components in the two tables in this case the poverty index explains $28 \%$ of total variance for men and $28 \%$ of total variance for women; second $18.1 \%$ for men and $15 \%$ for women; third $12.4 \%$ for men and $11.5 \%$ for women; fourth $10.2 \%$ for men and $10.7 \%$ for women. Also, the cumulative percentage of variance for Tables 6 (68.8\%) and Table 7 (66.7\%) accounted for by the current and preceding principal components shows that all variance is considered to be true and common variance (because it is principal component analyzed). Therefore, the variables are taken to be measured without error, so there is no error variance.

The most critical for determining the composition of the poverty index is the component rotated matrix shown in Table 7 for both males and females. This is because it consists of an index showing the coefficients' combination for each component called the "component loadings" which is the most important determinant for developing a poverty index. Components-loading coefficients represent the amount of correlation between the component variable and the indicator variable (Henry et al. 2003). Table 7 showed the result of the rotated component matrix for indicator measurements of men and women in the study area. The absolute value of the coefficients for each indicator represents the degree of correlation between the component and the indicator. Therefore, large absolute values indicate a high level of correlation, while low values indicate a lower level of correlation. Positive coefficients indicate the direction of the relationship between the indicator and the relative wealth of the household, hence as the value of the indicator increases, so does the value of the component which in this case is the relative wealth of households. Negative coefficients indicate an inverse relationship between the indicator and the relative wealth of the household.

Results of principal components analysis (Table 7), showing the significant components loadings of 0.50 and above in explaining indicators of poverty shows that for men, five factors loaded on Component 1: Materials for wall construction (0.662), Flooring materials ( -0.661$)$, Roofing materials (0.694), Sleeping materials (0.533) and Source of Illumination $(0.720)$ and are tagged Dwelling condition. For women, four factors loaded on Component 1: Materials for wall construction (0.800), Flooring materials $(-0.798)$, Roofing materials (0.834), and Source of Illumination (0.588) and are tagged Dwelling condition. This accounted for $28 \%$ for men and 29\% for women of the total variance explained.

Component 2 had three factor loadings for men and women. They are for men: Number of Dependent relatives (0.574), Method of treatment $(-0.513)$, Number of meals per day (0.705) and are tagged Quality of life which accounted for $18.2 \%$ of the total variance explained; for women: Number of dependent relatives $(0.560)$, Method of treatment $(-0.555)$, Sleeping material $(-0.517)$. This accounts for $15.1 \%$ of the total variance explained and is also named Quality of life.

Component 3 had two factor loadings for men. They are Annual income (-.509) and Source of farm Labour (0.706). This is tagged Economic condition and it accounted for $12.4 \%$ of the total variance explained. However, there is only one factor loading for women (Income (0.731) and this accounts for $11.5 \%$ of the total variance explained, and it is also named Economic condition.

Component 4 had one factor loading each for men, Year of schooling (0.649) which accounted for $10.2 \%$ of the total variance explained, and women, Source of farm labour (0.509) which accounted for $10.7 \%$ of the total variance explained. The factor loadings were not tagged because they did not show any clear-cut pattern. 
Tab. 7 Rotated component matrix for men and women.

\begin{tabular}{|c|c|c|c|c|c|c|c|c|}
\hline & \multicolumn{8}{|c|}{ Component } \\
\hline & \multicolumn{4}{|c|}{ MEN } & \multicolumn{4}{|c|}{ WOMEN } \\
\hline & 1 & 2 & 3 & 4 & 1 & 2 & 3 & 4 \\
\hline Annual income & -.347 & .384 & -.509 & .476 & -.252 & .313 & .731 & .255 \\
\hline Number of dependent relatives & -.419 & .574 & .388 & -.178 & -.348 & .560 & .188 & .430 \\
\hline Wall materials & .662 & .400 & -.380 & -.110 & .800 & .390 & .123 & -.061 \\
\hline Roofing materials & .694 & .430 & -.193 & -086 & .834 & .363 & -.094 & -.028 \\
\hline Floor materials & -.661 & -.431 & -.067 & -.051 & -.798 & -.259 & -.178 & -.067 \\
\hline Source of illuminations & .720 & .084 & .281 & -.241 & .588 & -.315 & -.123 & .123 \\
\hline Method of treatment & .487 & -.513 & .142 & -.151 & .329 & -.555 & -.258 & .392 \\
\hline Year of schooling & .533 & -.171 & .004 & 649 & .342 & -.517 & .242 & .390 \\
\hline Number of meals per day & -.302 & .705 & .215 & -.029 & -.334 & .192 & -.417 & .480 \\
\hline Source of farm labour & .168 & .109 & .706 & .485 & .324 & .189 & -.453 & .509 \\
\hline
\end{tabular}

Extraction method: Principal component analysis

Rotation method: Varimax with Kaiser normalization

Source: Author's survey

The combinations of the various factors named above accounted for $68.8 \%$ of the total variance explained for Men and $66.7 \%$ for Women. This constitutes the combinations of indicators that gave the most appropriate explanations to the underlying relative poverty variation between men and women in the study area.

In determining the poverty status of men and women in the study area, poverty index was used. This according to Henry et al. (2003) is a tool to measure the extent to which a household is worse off or better off compared to other households. The poverty index created through principal component extraction assigned poverty ranking scores to each household automatically. The lower the score, the poorer the household relative to all others with higher scores. The ranking made use of $33.3 \%$ to define the poorest group. The cut-off score for each tercile defines the limit of each poverty group (Henry et al. 2003). Since 198 men and women were the sampled population, then there should be approximately at least 33 men and 32 women in each group as shown in the frequency distribution in Table 8. The ranking revealed that more than twothirds of the men and women population fell between middle and high poverty groups in the study area.

Independent T-test as presented in Table 9 was used to test the hypothesis, which states that there is no significant difference in the poverty level among men and women. The test compared the difference in means of poverty scores and men and women. The independent sample t-test result as shown in Table 9 shows that the t-value of 4.098 and 4.131 is significant at 0.05 . A probability of 0.000 indicates that there is a significant difference between the poverty level between men and women in the study area. Thus, the hypothesis which states that there is a significant difference among men and women is accepted. This implied that the poverty level among men and women differs by gender in the study area.

Tab. 8 Frequency distribution of poverty groupings by gender.

\begin{tabular}{|l|r|r|r|r|}
\hline \multicolumn{1}{|c|}{ Poverty grouping } & Men & Cumulative percent (men) & Women & Cumulative percent (women) \\
\hline Low & $33(36.0 \%)$ & 32.7 & $32(33.0 \%)$ & 33.0 \\
\hline Middle & $34(32.0 \%)$ & 66.3 & $33(34.0 \%)$ & $65(34.5 \%)$ \\
\hline High & $34(32.0 \%)$ & 100.0 & $32(33.0 \%)$ & $67(33.0 \%)$ \\
\hline Total & $101(100.0 \%)$ & & $97(100.0 \%)$ & 100.0 \\
\hline
\end{tabular}

Tab. 9 Independent t-test of poverty groupings by gender.

\begin{tabular}{|c|c|c|c|c|c|c|c|c|c|}
\hline & & & \multicolumn{7}{|c|}{ t-test for equality of means } \\
\hline & \multirow{2}{*}{\multicolumn{2}{|c|}{ TOWN }} & \multirow[t]{2}{*}{$\mathbf{t}$} & \multirow[t]{2}{*}{ Df } & \multirow{2}{*}{$\begin{array}{c}\text { Sig. } \\
\text { (2-tailed) }\end{array}$} & \multirow{2}{*}{$\begin{array}{l}\text { Mean } \\
\text { difference }\end{array}$} & \multirow{2}{*}{$\begin{array}{l}\text { Std. error } \\
\text { difference }\end{array}$} & \multicolumn{2}{|c|}{$\begin{array}{c}95 \% \text { confidence interval } \\
\text { of the difference }\end{array}$} \\
\hline & & & & & & & & Lower & Upper \\
\hline \multirow{2}{*}{ OYO } & \multirow{2}{*}{ POVINDEX } & $\begin{array}{l}\text { Equal variances } \\
\text { assumed }\end{array}$ & 4.098 & 236 & .000 & .47408259 & .11568023 & -.70198038 & -.24618481 \\
\hline & & $\begin{array}{l}\text { Equal variances } \\
\text { not assumed }\end{array}$ & 4.131 & 221.6 & .000 & .47408259 & .11475052 & -.70022426 & -.24794093 \\
\hline
\end{tabular}


Figure 3 and Table 10 reflected the poverty levels of men and women by settlements in Atisbo local government area of Oyo state. This was done by cross-tabulating poverty groupings by gender and selected rural settlements in Atisbo local government area of Oyo state. In Opaba settlement, 20.4\% of the respondents had a low poverty level. $6.1 \%$ were males while $14.3 \%$ were females. This set of people had a steady income and their earnings were better than the predominant farmers. 55.9\% had medium poverty level, $28.6 \%$ were females and $27.3 \%$ were males. Also, $22.4 \%$ of the females had high poverty levels of while $1.3 \%$ of the males had high poverty levels. The majority of the respondents that had middle poverty levels were predominantly dependent on farming as their means of livelihood. Most of the farmers in this area owned and operated nearby commercial farms. Their cultivation equipment was machines (tractors), hoes, and cutlasses which form the major farm implements. Poultry farming and animal husbandry were also widely practiced by the farmers. Those that had high poverty levels were petty traders dominated by women.
In Babanla settlement, $40.4 \%$ of the respondents had a low poverty level. $26.9 \%$ were males while $13.5 \%$ were females. $13.4 \%$ had medium poverty level, $7.7 \%$ were males while $5.7 \%$ were females. $46.1 \%$ had a high poverty level, $11.5 \%$ were males while $34.6 \%$ were females. It is assumed that most of the respondents with low poverty levels were migrants who are majorly into smuggling activities. This was observed from the fairly used vehicles parked in their compounds with foreign plate numbers indicating their smuggling activities. Also, many of the migrants in this area are traders and secondary farmers who are economically active.

Also, in Budowule settlement, the majority of the respondents $(67.6 \%)$ had a very high poverty level. $30.8 \%$ were males while $36.8 \%$ were females. $16.9 \%$ of the respondents had medium poverty level, $8.5 \%$ were males while $8.4 \%$ of the respondents were females. The remaining $15.5 \%$ had a low poverty level. $13.4 \%$ were males while $2.1 \%$ were females. The majority of the migrants here are elderly. They have a high poverty level because these sets of people were weak physically and they were also economically inactive.

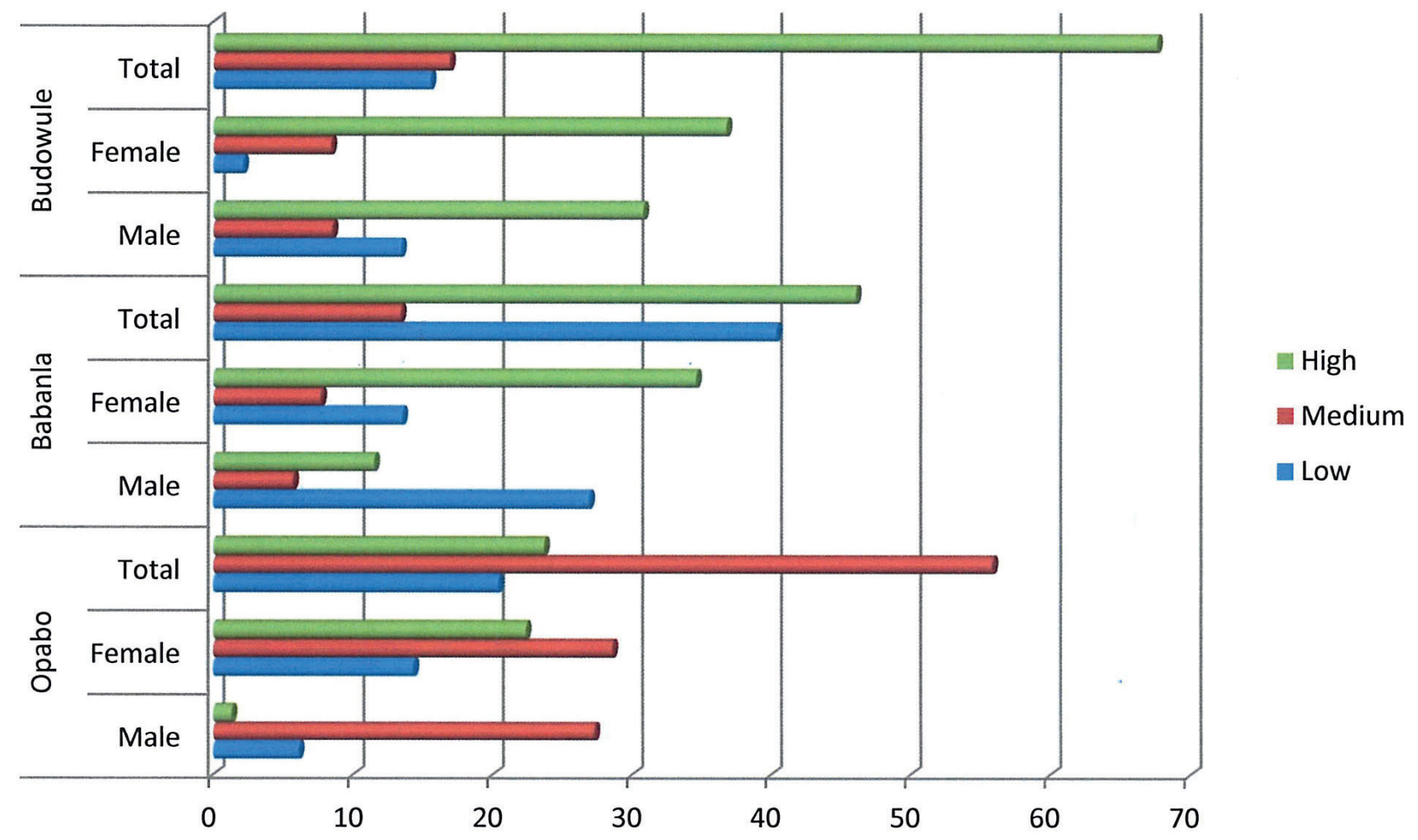

Fig. 3 Poverty levels of men and women in the selected rural communities of Atisbo local government area.

Source: Author's survey 
Tab. 10 Poverty levels of men and women in the rural border communities of Atisbo and Saki west LGA of Oyo State.

\begin{tabular}{|c|c|c|c|c|c|c|}
\hline \multirow{2}{*}{ LGA } & \multirow{2}{*}{ Settlement } & \multirow{2}{*}{ Gender } & \multicolumn{3}{|c|}{ Poverty level } & \multirow{2}{*}{ Total } \\
\hline & & & Low & Medium & High & \\
\hline \multirow{9}{*}{ Atisbo } & \multirow{3}{*}{ Opaba } & Male & 6.1 & 27.3 & 1.3 & 34.7 \\
\hline & & Female & 14.3 & 28.6 & 22.4 & 65.3 \\
\hline & & Total & 20.4 & 55.9 & 23.7 & 100.0 \\
\hline & \multirow{3}{*}{ Babanla } & Male & 26.9 & 5.7 & 11.6 & 44.2 \\
\hline & & Female & 13.5 & 7.7 & 34.6 & 55.8 \\
\hline & & Total & 40.4 & 13.4 & 46.1 & 100.0 \\
\hline & \multirow{3}{*}{ Budowule } & Male & 13.4 & 8.5 & 30.8 & 52.7 \\
\hline & & Female & 2.1 & 8.4 & 36.8 & 47.3 \\
\hline & & Total & 15.5 & 16.9 & 67.6 & 100.0 \\
\hline \multirow{9}{*}{ Saki west } & \multirow{3}{*}{ Okerete } & Male & 28.6 & 30.7 & 6.7 & 6.7 \\
\hline & & Female & 2.0 & 14.3 & 18.4 & 18.4 \\
\hline & & Total & 30.6 & 45.0 & 25.1 & 25.1 \\
\hline & \multirow{3}{*}{ Aiyemojuba } & Male & 10.0 & 22.5 & 15.0 & 47.5 \\
\hline & & Female & 7.5 & 17.5 & 27.5 & 52.5 \\
\hline & & Total & 17.5 & 40.0 & 42.5 & 100.0 \\
\hline & \multirow{3}{*}{ Abata gbooro } & Male & 34.7 & 12.7 & 6.7 & 54.1 \\
\hline & & Female & 1.7 & 3.5 & 40.7 & 45.9 \\
\hline & & Total & 36.4 & 16.2 & 47.4 & 100.0 \\
\hline
\end{tabular}

Source: Author's survey

Figure 4 and Table 10 reflect the poverty levels of migrant men and women in the selected rural border communities of Saki west local government area of Oyo state. This was done by cross-tabulating poverty groupings by gender and selected rural settlements in Saki west local government area of Oyo state. In Okerete settlement, $30.6 \%$ of the respondents had a low poverty level. $28.6 \%$ were males while $2.0 \%$ were females. $45 \%$ had medium poverty level, $30.7 \%$ were males while $14.3 \%$ were females. Also, $25.1 \%$ had a high poverty level, $6.7 \%$ were males and $18.4 \%$ were females. This may likely be because the migrants in this settlement enjoyed their nearness to the neighbouring country (Benin Republic). For instance, most of the migrants have direct opportunity of crossing the border without any barrier, hence improving their poverty status.

In Aiyemojuba settlement, $40 \%$ of the respondents had medium poverty level. $22.5 \%$ were males while $17.5 \%$ were females. $42.5 \%$ had a high poverty level, $15 \%$ were males while $27.5 \%$ were females. $17.5 \%$ had a low poverty level, $10 \%$ were males while $7.5 \%$ were females. This pattern might be because the respondents are at a distant location to the border towns and also the deplorable condition of the road which limited their products to their village and thus denied them the accessibility of the farm inputs and sale of their products. Also, in Abata gbooro settlement, $47.4 \%$ of the respondents had a high poverty level. $40.7 \%$ were females and $6.7 \%$ were males. $36.4 \%$ had a low poverty level, $34.7 \%$ were males while $1.7 \%$ were females. The remaining $17.1 \%$ of the respondents had medium poverty level, $12.7 \%$ were males while $3.5 \%$ were females. The reason for the high poverty level may likely be because their settlement has been cut off due to bad roads, thereby inhibiting effective transportation of goods and persons to and from the market. This invariably affected the rate at which farm products get spoilt and the result is a low income to the migrants.

ANOVA analysis in Table 11 was used to test the second hypothesis, which states that there no variation in the poverty level of men and women across the settlements in the study area. The result shows whether there is significant variation in the poverty level of men and women across the settlements. The ANOVA result as presented in Table 11 shows that the f-value of 33.718 is significant at 0.05 . A probability of 0.000 indicates that there is significant variation in the poverty level of men and women across the settlement. Hence, the hypothesis which states that there is significant variation in the poverty level of men and women across the settlements is accepted. This implied that the poverty level of men and women across the settlement varies in the study area. One of the reasons for this variation may be due to differences in the status of the settlement. 


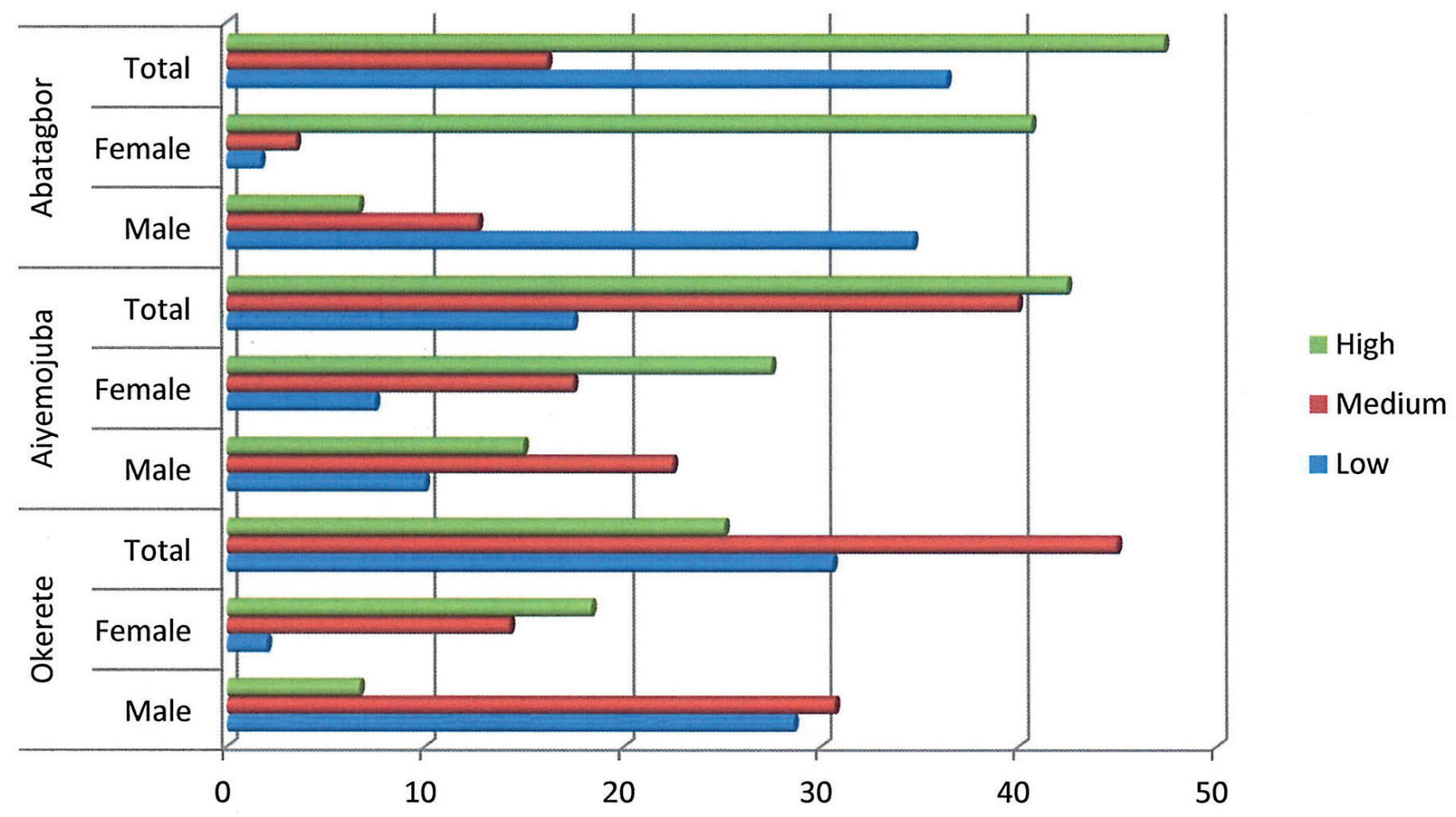

Fig. 4 Poverty levels of men and women in the rural border communities Saki west. Source: Author's survey

Tab. 11 ANOVA analysis showing variation in poverty level across the settlements.

\begin{tabular}{|c|c|c|c|c|c|c|}
\hline \multicolumn{7}{|c|}{ POVINDEX } \\
\hline \multicolumn{2}{|c|}{ Across the Settlements } & Sum of Squares & df & Mean Square & $\mathbf{F}$ & Sig. \\
\hline \multirow{3}{*}{ OYO } & Between Groups & 67.129 & 5 & 13.426 & 33.718 & .000 \\
\hline & Within Groups & 76.450 & 192 & .398 & & \\
\hline & Total & 143.579 & 197 & & & \\
\hline
\end{tabular}

Source: Author's Survey

\section{Conclusion and Recommendation}

The study determined the extent of poverty between men and women in the selected rural border communities of Oyo State using poverty index created through principal component analysis. The study revealed there were variations in the poverty levels of men and women and these variations were further shown across the selected rural border communities. It was also evident in the study that women have high poverty levels than men in the study area. The results of the t-test show that there is a significant difference in the poverty scores between men and women. It was discovered that there is significant variation in the poverty level of men and women across the settlements. By implications, it means it will be possible to distinguish between those with low poverty levels from high poverty levels in the area. This is necessary for poverty interventions as it may not be possible to target all the poor at once. Also, there is need to focus on gender-based poverty interventions especially among females in all the settlements as they have been found to be more affected by poverty than males in this study.

Also, the high loadings of factors on components one for men and women which were tagged Dwelling Conditions indicates poor housing condition. The study suggested the need to improve the dwelling conditions of the migrants for instance by using modern building materials for their houses. Also, rural housing programs where people are trained in the act of using modern materials to build houses should be encouraged. In addition, cooperative societies and community-based housing cooperatives should be established in order to enable rural border residents to have access to loans, credit facilities, and building materials to build their own homes.

\section{Reference}

Adeyonu, A. G., Oni, O. A. (2014): Gender Time Allocation and Farming Households Poverty in Rural Nigeria. World Science Research Journals 2(5), 123-136. 
Ahadzie, D. K., Proverbs, D. G., Olomolaiye, P. O. (2008): Model for Predicting the Performance of Project Managers at the Construction Phase of Mass House Building Projects. Journal of Construction Engineering and Management 134(8), 618-629, https://doi .org/10.1061/(ASCE)0733-9364(2008)134:8(618).

Alaye-Ogan, E. O. (2008): Rural Poverty among Women in Nigeria: A Case Study of Abuja Satellite Communities of Nigeria. A Ph.D. Thesis Submitted to the School of Post Graduate Studies, St Clements University, Turks and Caicos Islands, British West Indies.

Alkire, S., Foster, J. (2011): Counting and Multidimensional Poverty measurement. Journal of Public Economics 95(7-8), 476-487, https://doi.org/10.1016/j .jpubeco.2010.11.006.

Alkire, S., Sumner, A. (2013): Multidimensional Poverty and the Post-2015 MDGs. OPHI Briefing Note, https://doi .org/10.1057/dev.2013.6.

Alkire, S., Kanagaratnam, U., Nogales, R., Suppa, N. (2020). Revising the global Multidimensional Poverty Index: Empirical insight and robustness', OPHI Research in Progress 56a, Oxford Poverty and Human Development Initiative, University of Oxford. https://ophi.org.uk /rp56a.

Anyebe, A. G. (2017): Gender Differential and Poverty Amongst Women in Nigeria. International Journal of Academic Research in Business and Social Sciences 7(4), 81-86, https://doi.org/10.6007/IJARBSS/v7-i4/2781.

Apata, T. G., Apata, O. M., Igbalajobi, O. A., Awoniyi, S. M. O. (2010): Determinants of rural poverty in Nigeria: Evidence from Small holder farmers in South-western, Nigeria. Journal of Science and Technology Education Research 1(4), 85-91.

Awumbila, M. (2015): Women moving within Borders: Gender and Internal Migration dynamics in Ghana. Ghana Journal of Geography 7(2), 132-145.

Ayoade A. R., Adeola, R. G. (2012): Effects of Poverty on Rural Household Welfare in Oyo State, Nigeria. Global Journal of Science Frontier Research Agriculture and Biology 12(4), https://globaljournals.org /GJSFR_Volume12/6-Effects-of-Poverty-on-Rural -Household-Welfare.pdf.

Chambers, R. (2006): Revolutions in Development Inquiry. London: Earthscan.

Chambers, R. (2007): Participation, pluralism and perceptions of poverty. In: Kakwani N., Silber J. (eds.) The Many Dimensions of Poverty. Palgrave Macmillan, London. https://doi.org/10.1057/9780230592407_8.

Chen, C., Pan, J. (2019): The effect of the health poverty alleviation project on financial risk protection for rural residents: Evidence from Chishui City, China. International Journal for Equity in Health 18(79), 1-16, https://doi.org/10.1186/s12939-019-0982-6.

DFID (2005): Reducing Poverty by Tackling Social Exclusion: A DFID Policy Paper, Department for International Development, London, https://www2 .ohchr.org/english/issues/development/docs /socialexclusion.pdf.

Fadare, S. O., Gasu, M. B. (2011): Study of poverty in rural hinterlands of Ede, Nigeria. Ife Journal of Environmental Design and Management 5, 1-14.

Fapohunda, T. M. (2012): Women and Poverty Alleviation in Lagos, Nigeria. British Journal of Humanities and Social Sciences 3(2), 87-99.
FAO (2019): FAO Migration Framework - Migration as a choice and an opportunity for rural development. Food and Agriculture Organization of the United Nations Rome. 128, http://www.fao.org/3/ca3984en /CA3984EN.pdf.

Gweshengwe, B., Hassan, N. H. (2020): Defining the characteristics of poverty and their implications for poverty analysis, Cogent Social Sciences 6(1), 1768669, https://doi.org/10.1080/23311886.2020.1768669.

Hao, J., Zhang, P., Yu, W. (2021): Gender differences in rural education in china. Asian Journal of Women's Studies 27(1), 66-86, https://doi.org/10.1080/12259276.2021 .1893924 .

Henry, C., Lapenu, C., Zeller, M., Sharmma, M. (2003): Microfinance Poverty Assessment Tool. Washington, DC: The World Bank, https://doi .org/10.1596/0-8213-5674-7.

IFAD (2007): Rural Poverty Portal; Geography, agriculture and the economy. https://www .ifad.org/documents/38714170/39309772 /annual+report+2007+e. pdf/7873ffb5-eb18-4121-b0a0-4dc591624468.

IFAD (2014): The Multidimensional Poverty Assessment Tool. International Fund for Agricultural Development, https://www.ifad.org/documents/38714170/40302999 /The+Multidimensional+Poverty+Assessment+Tool +User's+guide.pdf/2fa7cc27-343b-4c22-93f2 -eeef5b17f1c8.

IOM (2019): World Migration Report 2020, McAuliffe, M., Khadria, B. (eds.), Geneva, https://doi.org/10.1787 /ECO_SURVEYS-USA-2018-EN.

Jawando, J. O., Adeyemi, E. O., Oguntola-Laguda, B. (2012): Survival Strategies of women in informal cross Border Trade along Lagos-Seme Border Axis. Global Journal of Human Social Science Sociology, Economics and Political Science 12(9), 29-37, https://globaljournals.org/GJHSS _Volume12/5-Survival-Strategies-of-Women.pdf.

Koehler, G. (2017): The 2030 Agenda and eradicating poverty: New horizons for global social policy? Global Social Policy 17(2), 210-216, https://doi .org/10.1177/1468018117703440.

Lyimo-Macha, J., Mdoe, N. (2002): Gender and rural poverty in Tanzania: case of selected villages in Morogoro rural and Kilosa districts. Draft. LADDER Working Paper No. 18.

Makinwa-Adebusoye, P. K. (1994): Women Migrants in Nigeria. International Sociology. 9(2), 223-236.

Naderifar, M., Goli, H., Ghaljaie, F. (2017): Snowball Sampling: A Purposeful Method of Sampling in Qualitative Research. Strides in Development of Medical Education 14(3), 1-6, https://doi.org/10.5812 /sdme.67670.

Nkoroi, I. (2015): Assessing the Informal Cross Border Trade Between Kenya and Uganda. An M.Sc Thesis submitted to the institute of Diplomacy and international studies, University of Nairobi, http://erepository.uonbi .ac.ke/bitstream/handle/11295/92997/Nkoroi,\%20 Isaac_Assessing\%20the $\% 20$ informal $\% 20$ cross $\% 20$ border $\% 20$ trade $\% 20$ between $\% 20$ Kenya $\% 20$ and $\% 20$ Uganda.pdf?sequence $=3$.

Ogbonna, M. C., Onyenweaku, C. E., Nwaru, J. C. (2012): Determinants of Rural Poverty in Africa: The case of Yam farm households in South Eastern Nigeria. International Journal of Agriculture and Rural Development 15(2), 1129-1137. 
Oladehinde, G. J., Popoola, K., Fatusin, A., Adeyeni, G. (2017): Land Accessibility Characteristics among Migrants in Yewa North Local Government Area of Ogun State, Nigeria. Asian Research Journal of Arts and Social Sciences 2(1), 1-12, https://doi.org/10.9734 /ARJASS/2017/30086.

OPHI (2018): Global Multidimensional Poverty Index 2018: The Most Detailed Picture to Date of the World's Poorest People, University of Oxford, UK. https://ophi.org.uk /wp-content/uploads/G-MPI_2018_2ed_web.pdf.

Popoola, K. O., Speak, S. E. (2018): Accessing and utilizing services by rural border communities in South Western Nigeria. Economic and Environmental Studies 18(48), 1335-1349.

Popoola, K. O., Oladehinde G. J., Fatusin, A. F. (2017): Gender Analysis of Cross-border Migration in Rural Border Communities of Ipokia Local Government Area, Ogun State, Nigeria. Economic and Environmental Studies 17(2), 165-184.

Sen, A. K. (1999): Development as freedom. New York: Knopf.

Strachan, G., Adikaram, A., Kailasapathy, P. (2015): Gender (In)Equality in South Asia: Problems, Prospects and Pathways. South Asian Journal of Human
Resources Management 2(1), 1-11, https://doi .org/10.1177/2322093715580222.

United Nations Department of Economic and Social Affairs, Population Division (2013): Trends in International Migrant Stock: The 2013 Revision, https://www.un.org /en/development/desa/population/migration/data /estimates2/estimatestotal.asp.

UNDP and OPHI (2020). Global Multidimensional Poverty index 2020 - Charting Pathways out of Multidimensional Poverty: Achieving the SDGs. Report. Unite Nations Development Programme and Oxford Poverty and Human Development Initiative, https://ophi.org.uk /global-mpi-report-2020.

Usman, U. S. (2015): Women and Poverty in Nigeria: Agenda or poverty eradication. Developing Country Studies 5(3), 1-6.

World Bank (1990): Poverty World Development Policy Staff Paper, Washington D.C. https://openknowledge .worldbank.org/bitstream/handle/10986/5973 /WDR\%201990\%20-\%20English.pdf?sequence=5.

Yichao, W., Di, Q. (2017): A gender-based analysis of multidimensional poverty in China. Asian Journal of Women's Studies 23(1), 66-88, https://doi.org/10.1080 /12259276.2017.1279886. 